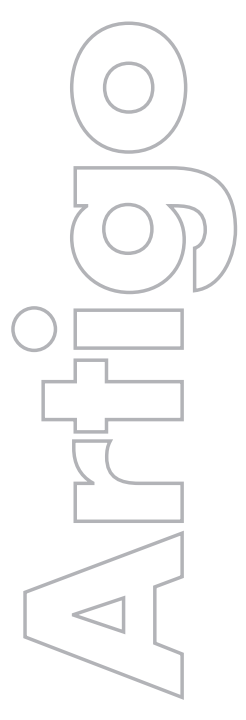

revista

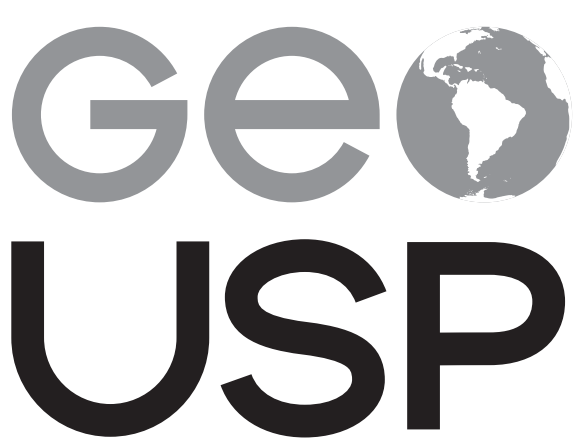

espaço e tempo

Volume $21 \cdot n^{\circ} 2$ (2017)

ISSN 2179-0892
Urbanização e cidade dispersa: implicações da produção do espaço urbano no Brasil, em Moçambique e na Austrália

Lindberg Nascimento Júnior

Unesp

p. $550-569$

Como citar este artigo:

NASCIMENTO JÚNIOR, L. Urbanização e cidade dispersa: implicações da produção do espaço urbano no Brasil, em Moçambique e na Austrália. Geousp - Espaço e Tempo (Online), v. 21, n. 2, p. 550-569, agosto. 2017. ISSN 2179-0892.

Disponível em: < http://www.revistas.usp.br/geousp/ article/view/125392>. doi: 10.11606/issn.2179-0892. geousp.2017.125392.

\section{(c) $(1) \Theta$}

Este artigo está licenciado sob a Creative Commons Attribution 4.0 License. 


\title{
Urbanização e cidade dispersa: implicações da produção do espaço urbano no Brasil, em Moçambique e na Austrália
}

\section{Resumo}

Imagens de luzes noturnas dos anos de 1992, 2002 e 2012 foram tratadas para o território brasileiro, moçambicano e australiano a fim de suscitar uma discussão comparada da dispersão urbana nos países do Hemisfério Sul. No debate, considerou-se a ideia da dispersão urbana como fundamento da distinção entre urbanização (processo) e cidade (forma), articulando esses conceitos à intensidade e à expansão das luzes noturnas nas áreas dos países estudados. A revisão bibliográfica e o tratamento das imagens por técnicas de sensoriamento remoto possibilitaram interpretar, quantificar e mapear áreas iluminadas e não iluminadas. Esses procedimentos ajudam a inferir atributos semelhantes e diferentes nos níveis globais e regionais dos países estudados, como medida de particularização da dispersão urbana em diferentes formações socioespaciais.

Palavras-chave: Dispersão urbana. Imagens de luzes noturnas. Sensoriamento remoto. Infraestrutura urbana.

\section{Urbanization and urban sprawl: implications in Brazil, Mozambique and Australia of urban space's production}

\begin{abstract}
Nightlights from 1992, 2002 and 2012 years were treated for Brazilian, Mozambican and Australian territories. The aim is offer a comparative discussion of urban sprawl in the Southern Hemisphere. We used the intensity and expansion of nighttime stable light as a element of urban sprawl that distinguish the urbanization (process) and city (form). In general, the quantification and mapping in illuminated and unlighted areas shows similarity and difference attributes of global and regional levels, and the urbanization as a measure of particularization of urban sprawl under different sociospatial formations.
\end{abstract}


Keywords: Urban sprawl. City. Nightlights images. Remote sensing. Urban infrastructure.

\section{Introdução}

A produção da cidade não ocorre de forma natural e espontânea. Trata-se de um projeto social orientado, que intencionalmente consolida as lógicas de reprodução das relações sociais de produção e sintetiza as problemáticas relacionadas aos modos de vida da sociedade e dos homens (Lefebvre, 1975).

As leituras possíveis para interpretação desse quadro colocam em destaque uma questão e uma teoria eminentemente geográfica, resultantes da associação de universos que conjugam a cidade como forma (fato, físico e territorial), a urbanização como processo (teórico, histórico e social), e o urbano (modo de vida e de produção) como conteúdo de ambos (Santos, 1993).

Nessa leitura, o interesse é não desvincular o exercício dialético entre o conteúdo (urbano) e a expressão material da dinâmica social urbana. Essa atividade se institui no âmbito de uma formação social na cidade (forma), e também, na dimensão histórica, do movimento da sociedade em seus aspectos econômicos, políticos, artísticos e culturais, inerentes à urbanização (processo) (informação verbal)' (Santos, 1993).

Dito isso, pode-se considerar que atualmente a cidade se constitui pela expansão do tecido urbano ou da mancha urbana em direção às áreas vizinhas, diferente de outros momentos da história nos quais ela foi caracterizada de forma compacta e territorialmente restrita (Bruegmann, 2005; Sposito, 2007; Botelho, 2012; Catalão, 2013).

De certa maneira, o processo no qual a cidade está submetida marca também a gênese dos problemas ambientais e urbanos da modernidade. Esses se dão pela: (a) ruptura da continuidade territorial urbana (Sposito, 2005); (b) produção de vazios e intensificação da diferenciação socioespacial (Sposito, 2010; Ojima; Marandola Jr., 2016); (c) ocupação de áreas susceptíveis ou expostas a perigos e riscos naturais (Nunes, 2015); e, (d) pela precariedade na oferta e qualidade de infraestruturas urbanas (Ojima; Monteiro; Nascimento, 2015).

Não se trata de um contexto inédito, mas, sem dúvida, é um momento que oferece a possibilidade de incluir na análise outros conteúdos atinentes aos processos de urbanização relativos ao modo de produção capitalista. Um atributo que, passível de crítica e de questionamentos, favorece a reflexão sobre os fundamentos do fenômeno urbano, do viver na cidade e sob quais modelos de urbanização e de cidades a humanidade caminha.

Ciente de que a elaboração de uma leitura coerente e totalizante do fenômeno urbano carece de fôlego e aprofundamento nos estudos da temática, este trabalho aborda, mais precisamente, a discussão do par urbanização-cidade, limitando-o às possibilidades teóricas, metodológicas e instrumentais aqui apresentadas.

Entende-se que o par urbanização-cidade proporciona desvendar parte dos processos socioespaciais, ademais, destaca o protagonismo pretérito da urbanização como estruturador da cidade. Conforme Lefebvre (1975), nesta leitura, a urbanização é totalização (movimento), e a cidade é um momento no movimento da totalização.

1 Informação fornecida por Sposito, em sala de aula, em 2014. 
Desse modo, com vias a oferecer uma proposta interpretativa da urbanização hodierna, elaborou-se um estudo comparado que analisa três países do Hemisfério Sul: Brasil, Moçambique e Austrália. $O$ estudo baseou-se na utilização de imagens de satélite do tipo luzes noturnas, atribuindo-as uma funcionalidade técnica que pode auxiliar na observação da expansão das cidades. Para tanto, tem-se como base a implantação de infraestrutura de energia, e o contraste, representado entre áreas iluminadas e não iluminadas.

\section{Da dispersão urbana à cidade dispersa}

As transformações e mudanças atuais da constituição das cidades, além dos modelos de urbanização, têm produzido outras configurações no mundo urbano. A evidência de fragmentações, descontinuidades e baixa densidade, que se diferem sobremaneira da tradicional cidade compacta (Gonçalves, 2011), coloca a dispersão urbana como uma das principais características do atual momento da história urbana (informação verbal)2 (Bruegmann, 2005; Sposito, 2007; Botelho, 2012; Catalão, 2013).

A designação dispersão urbana é equivalente ao urban sprawl do inglês e étalement urbain do francês. Esse termo explica a expansão horizontalizada, espraiada, e não compacta do tecido urbano, ${ }^{3}$ desse modo, trata-se da extensão da configuração do tecido urbano (maIha, ambiente construído, vias etc.), conformando núcleos urbanos dispersos e territorialmente descontínuos do conjunto urbano principal (Silva, 2013).

Tais núcleos urbanos são um tipo específico de expansão urbana, que se expressam em rupturas, com redefinições das lógicas de distribuição espacial dos usos residenciais, industriais, comerciais etc. Eles são caracterizados pela ocupação do solo com baixa densidade populacional em áreas periféricas, as quais conjugam diferentes formas de uso e cobertura da terra. E, por isso, é um tipo de urbanização que promove e exige maior consumo de energia, de recursos naturais e alterações ambientais (informação verbal) ${ }^{4}$ (Squires, 2002, Bruegmann, 2005; Sposito, 2007; Botelho, 2012; Amaro, 2016).

Botelho (2012) e Sposito (informação verbal) ${ }^{5}$ chamam atenção para o significativo número de termos e denominações que explicam a dispersão urbana e também para as diferentes concepções e interpretações dos autores. Os dois pesquisadores esclarecem que, tendo em vista essa característica, parte da complexidade da realidade urbana contemporânea se mostra como uma questão que pode e deve ser abordada por múltiplas dimensões e múltiplos olhares.

Botelho (2012) entende a dispersão urbana como dispersão do tecido urbano e organiza uma série de conceitos, conforme expressões em diversas línguas (lusas, hispânicas, germânicas e anglo-saxãs), que podem ser resumidas principalmente em: cidade dispersa, città difusa, zwischenstadt, tecnurbia, exurbia, edgecity, edgelesscity, limitlesscity, metápolis, exopolis.

autor (Botelho, 2012) categoriza em seis pontos as explicações sobre as causas da dispersão urbana contemporânea, conforme Quadro 1.

Essa classificação pode favorecer um aspecto interessante para o entendimento de diversas perspectivas e abordagens explicativas dessa problemática, principalmente o viés explicativo (primeira coluna), que abrange desde abordagens naturalistas e liberais até estadista e culturais.

2 Informação fornecida por Sposito, em sala de aula, em 2014.

3 Embora possa haver variações conceituais, neste texto, tecido urbano é sinônimo da cidade como forma e também equivale à área construída, mancha urbana, tecido urbano, entre outros conceitos relativos.

4 Informação fornecida por Sposito, em sala de aula, em 2014.

5 Informação fornecida por Sposito, em sala de aula, em 2014. 


\section{Quadro 1 - Vieses explicativos e interpretações da dispersão urbana se- gundo Botelho (2012)}

\begin{tabular}{lll}
\hline viés explicativo & entendimento da dispersão & lógica e elementos motivadores \\
\hline \multirow{3}{*}{ naturalista } & Consequência natural do cres- & Os moradores de áreas centrais conges- \\
& $\begin{array}{l}\text { cimento das cidades quando } \\
\text { adquirem certo grau de maturi- } \\
\text { dade e afluência. }\end{array}$ & $\begin{array}{l}\text { tionadas passam a ter a escolha de habitar } \\
\text { ção, baixos custos e espaços maiores. }\end{array}$ \\
\hline
\end{tabular}

$\begin{array}{ll} & \text { Possibilitada pela maior mo- } \\ \text { tecnicista } & \text { bilidade urbana e por avanços } \\ & \text { tecnológicos nos meios de trans- } \\ & \text { porte e nas comunicações. }\end{array}$

A carruagem, o trem, o bonde, o automóvel e a telemática foram, cada qual a sua maneira, produzindo a dispersão, ao proporcionar aos moradores dos subúrbios a necessária mobilidade, seja em direção a áreas urbanas centrais tradicionais ou a novos centros de trabalho, consumo e lazer.

$\begin{array}{ll} & \text { Devido ao sentimento antiurba- } \\ & \text { no, ligado ao ferrenho individua- } \\ \text { lismo e à busca por vizinhanças } \\ \text { homogêneas, dominante em al- } \\ \text { gumas sociedades, notadamente } \\ \text { as anglo-saxônicas. }\end{array}$

Com a expansão do american way of life, o padrão de moradia suburbana dos EUA passaria a ser adotado por outras sociedades da Europa, da Ásia e da América Latina.

Resposta ao efeito direto da economicista falta de regulação predominante do modo de produção capitalista e do crescimento urbano.
Estado é o agente fundamental para compreender a disper-

estatista

liberal
Seria o efeito da escolha individual e racional de membros e agentes da sociedade.
A busca pelo bem individual por parte de compradores e vendedores levaria a uma situação marcada pela especulação imobiliária e o espalhamento urbano que beira à irracionalidade no uso e na apropriação desigual de recursos naturais e da superfície edificada.

A concessão de subsídios e financiamento aos moradores dos subúrbios, a falta de controle sobre a ação dos agentes privados, o zoneamento e o planejamento que garantiriam a desejada homogeneidade funcional nos subúrbios, a oferta de infraestrutura viária que garantiria a acessibilidade às áreas mais afastadas dos centros tradicionais e a construção de conjuntos habitacionais para os mais pobres em áreas distantes do centro.

A opção pela moradia em áreas mais afastadas seria possível a parte da democratização do sistema político, que daria mais liberdade de escolha às famílias, tendo em vista a prosperidade causada pelo crescimento econômico e a garantia de mobilidade pelos meios de transporte. 
O interessante é que, na proposta de Botelho (2012), a polifonia presente na dispersão urbana abrange diferentes pontos de partida, colocando essa expressão também como um problema conceitual, teórico e empírico. Dimensões que convergem tanto para o entendimento do fenômeno como mais uma faceta da cidade moderna, quanto para as próprias convenções do que se denomina ou se entende por cidade, por urbanização e por urbano.

De outro modo, Sposito (informação verbal) ${ }^{6}$ preocupa-se mais com a dispersão urbana como novas formas de extensão do tecido urbano e oferece um exercício que articula a dialética do tripé: forma (cidade), processo (urbanização) e conteúdo (urbano). A autora também contempla, além dos termos discutidos por Botelho (2012), outros como: urbanização e cidades difusas, difusão reticular, rururbanização, cidade pós-moderna, cidade informacional, formas de assentamento humano e organização regional da vida urbana, outercities, cidades-região, pós-metrópoles e e-topia.

Para a autora, as cidades estão estruturadas sob a urbanização dispersa e que em linhas gerais se desenvolve de maneira mais desigual, uma vez que a dispersão do tecido urbano se dá na constituição de cidades territorialmente fragmentadas e socioespacialmente diferenciadas. Essa situação favorece cada vez mais rupturas e descontinuidades, que redefinem lógicas de distribuição espacial dos usos residenciais, industriais, comerciais e de serviços, que por sua vez indicam transformações profundas no uso da cidade e no modo de vida urbano (informação verbal). ${ }^{7}$

De forma abrangente, Bruegmann (2005) entende que a dispersão urbana é um fenômeno que esteve presente desde vilas das elites na Roma Antiga e nos bairros construídos fora das muralhas na Europa Medieval, no sentido que o distanciamento era um fator de comodidade ou estratégia para fugir das imposições e controles das autoridades.

Ainda, segundo o autor, mais recentemente, no século XIX é que o mundo observou o aumento importante do modo de vida urbano, e com ele, a configuração das malhas urbanas que transformaram as cidades em grandes regiões, mudando o contexto da rede urbana de muitos países (Bruegmann, 2005).

Nesse contexto, o sistema interpretativo da urbanização muda de qualidade. Ou seja, se antes a expansão urbana era limitada pelos padrões mínimos de densidade urbana, configurando assim a cidade compacta, isso muda na medida em que a expansão urbana acaba por se diluir pela possibilidade oferecida pelos automóveis e outros condicionantes do modo de vida urbano que atuam na acessibilidade, na disponibilidade de energia e de recursos, na relação entre distância e mobilidade e na viabilidade técnico-financeira (Bruegmann, 2005, p. 33).

Desse modo, se no primeiro momento, a concentração da população urbana e a importância das cidades como o lócus do poder promoveram o desenvolvimento dos meios de transporte (ferroviário, trens, bondes etc.), encurtando as distâncias entre bairros, cidades e regiões. É somente sob novos padrões de consumo, da consolidação do período técnico-científico-informacional, da popularização do automóvel e do desenvolvimento de infraestrutura de transportes nas cidades que a dispersão oferece à leitura da urbanização mais um grau generalização (informação verbal) ${ }^{8}$ (Bruegmann, 2005). 
Sobre esse aspecto, os veículos, principalmente os automóveis, permitiram outro tipo de mobilidade na cidade. Sua massificação nas primeiras décadas do século XX, portanto antes da Primeira Grande Guerra, promoveu a construção das cidades dos automóveis como um marco específico do período industrial e financeiro (informação verbal)9 (Bruegmann, 2005). Sendo o marco mais expressivo e consolidado no pós-guerra, as cidades dos automóveis, formadas a partir da "[...] implantação de sistemas de transporte urbano, primeiramente por trilhos (bondes e trens suburbanos, seguidos pelo metrô) e depois, o de matriz automotiva (ônibus, carros, caminhões, motos etc.), geraram condições técnicas e funcionais para uma cidade mais expandida" (Sposito, 2010, p. 72).

Esse foi um dos principais fatores que dotou a cidade menos compacta, "[...] alcançando a situação de dispersão do tecido urbano e de diluição clara das formas urbanas em amálgamas em que elas se mesclam aos espaços rurais nas franjas deste tecido" (Sposito, 2010, p. 72).

Se o uso de automóveis ofereceu outra qualidade ao desenvolvimento urbano, a expansão da cidade, a partir daquele momento, poderia se dá em e para qualquer direção. Em síntese, a dispersão urbana foi mais possível e mais efetiva com a inclusão de mais fluidez ao modo de vida urbano, tornando mais intenso e rápido processo de expansão do tecido urbano (Newman; Kenworthy, 1999, p. 31).

Sem isenção de aspectos contraditórios, a dispersão urbana se deu também em outras dimensões do espaço urbano. Não restritas ao tamanho e extensão, a questão carece cada vez mais de análises que valorizem dimensões múltiplas (Sposito, 2010; Botelho, 2012).

Isso por que essa nova realidade urbana complementa a redefinição do paradigma centro $x$ periferia em várias escalas. Esse par dialético que orientou, durante tanto tempo, as lógicas de estruturação dos espaços urbanos.

A produção do espaço urbano e as formas de sua apropriação foram, assim, reorientadas por novos interesses, apoiadas em novas condições tecnológicas e valores culturais, que construíram estruturas socioespaciais mais complexas e que, muitas vezes, podem congregar várias cidades ao mesmo tempo (Sposito, 2010).

Ojima e Marandola Jr. (2016) discutem parte desses aspectos qualificando a urbanização dispersa em duas dimensões: a da autossegregação e da periferização. A primeira se dá como possibilidade financeira e econômica de condições de localidade e moradia, baseada no poder de decisão e da escolha fundamentada no uso da cidade em espaços fechados ou em condomínios murados, que por vezes podem estar ou não distantes do centro (Ojima; Marandola Jr., 2016).

A segunda dimensão se caracteriza na qualificação de áreas habitadas por população com baixos rendimentos, nas quais o acesso aos terrenos e à moradia, muitas vezes afastados do centro, não funciona como um fator de decisão deliberada, mas uma imposição sobre quais lugares onde a população mais pobre deve morar. Habitualmente, são áreas parcamente atendidas por serviços de transporte, abastecimento de água, infraestrutura, eletricidade etc. (Ojima; Marandola Jr., 2016).

9 Informação fornecida por Sposito, em sala de aula, em 2014. 
Caracterizados pela densidade construtiva e pela consolidação de núcleos urbanos dissociados, os dois processos - autossegregação e periferização - auxiliam inclusive, e concomitantemente, na oferta e instalação de equipamentos sociais de uso coletivo (hospitais, escolas, áreas de lazer). Sob uma lógica induzida e orientada, esses equipamentos são o sinal de aceleração e seletividade dos processos de segregação socioespacial e desigualdade na cidade.

Os aspectos contraditórios da urbanização dispersa também se dão na dimensão ambiental, uma vez que o consumo exagerado de terras, água, energia, seus custos de instalação de infraestrutura, modelo de planejamento ${ }^{10}$ e baixo controle também geram um encadeamento de outros problemas (Bruegmann, 2005).

Nesse caso, o processo dá a qualidade da configuração da cidade, mas também permanece a apresentação de distintas características em relação aos padrões anteriores de urbanização. As transformações advindas dessas mudanças alteram a natureza dos impactos ambientais e agravam os problemas urbanos. Exemplos disso são: a retirada da vegetação e alteração dos terrenos por meio de mudanças no relevo, que são as primeiras repercussões da construção da cidade dispersa (Silva, 2013).

De todo modo, a dimensão ambiental da urbanização dispersa também, já que os custos dos impactos ambientais, em razão da diminuição do desempenho de funções ecológicas básicas em áreas que não foram submetidas à construção, oferecem mais um elemento de encarecimento por distância.

O encarecimento por distância se dá na medida em que a malha urbana é estendida, favorecendo a elevação de mais custos (públicos e privados) de uso da cidade. Trata-se dos custos agregados tanto no uso de transporte (individual ou coletivo), que se associa ao aumento no consumo de combustível (Smith; Doherty, 2006), quanto na elevação de investimentos em obras de infraestrutura, na oferta de serviços públicos e/ou coletivos, como energia, abastecimento de água, produção de alimentos, nas novas áreas.

Contudo, o encarecimento por distância é relativo. $\bigcirc$ que o processo sugere é a interpretação de uma série de mudanças de uso e ocupação do solo que são acompanhadas por fortes processos de especulação imobiliária orientada para valorização de determinados setores e áreas da cidade com mais vantagens para determinados grupos e agentes sociais. $\bigcirc$ processo, desse modo, age em conjunto e concomitância ora como periferização, ora como autossegregação.

Diferentemente, Garden e Jalaludin (2009) discutem que a urbanização dispersa também está associada a um problema de saúde pública, principalmente no que se refere às taxas de obesidade pelo aumento do consumo de alimentos tipo fast-food (altamente calóricos e pouco nutritivos) e ao sedentarismo.

$10 \bigcirc$ planejamento e o controle são entendidos como estratégias orientadas, segundo a intencionalidade dos agentes de produção do espaço urbano, que, sob o modo de produção capitalista, não permite que todos tenham direito à cidade. Nesse caso, a especulação e a valoração (efeito de determinar o valor de algo distinguindo a qualidade no preço, no encarecimento, no significado e no simbólico) de determinadas áreas e zonas da cidade, além de outros processos associados, são superpostos em detrimento dos valores ambientais, estéticos e sociais no plano urbano e de sua democratização. 
Garden e Jalaludin (2009) se apoiam nas teses debatidas de Zhao e Kaestner (2010) e da Organização Mundial da Saúde (World Health Organization) (WHO, 2003). Esses estudos refletem sobre o modelo de cidade dispersa, que tem entre outras características, a diminuição das caminhadas e da prática de esportes, somada ao consumo de fast-food. Esses elementos têm promovido não só o sobrepeso da população urbana, mas também, riscos de doenças como diabetes, cardiovasculares e certos tipos de câncer.

Segundo Amaro (2016), esse quadro é preocupante, uma vez que a baixa prevenção da obesidade e o uso cada vez mais intenso de automóveis em longas distâncias significam também uma população menos produtiva, com maiores gastos com saúde pública.

Contudo, a relação entre urbanização dispersa e os índices de obesidade ainda não está claramente explicada. Nos EUA, Eid e outros (2008) observaram indivíduos ao longo do tempo e não encontram evidências da relação entre cidade dispersa e aumento da obesidade. Para esses autores, a leitura que relaciona os dois eventos é equivocada. E segundo estes autores, as observações anteriores provavelmente refletem a incapacidade de controle adequado ao fato de que os indivíduos com maior probabilidade de serem obesos escolherem e viverem nos bairros mais afastados.

Já para Eid e outros (2008), a cidade dispersa se relaciona com muito mais significância aos níveis socioeconômicos (diferentes rendimentos salariais e raça principalmente) como o mecanismo causador e que impulsiona as diferenças observadas nas características individuais de residência no contexto estadunidense.

Diante dessas leituras, em síntese, os conceitos de autossegregação, periferização, degradação ambiental, encarecimento por distância e qualidade na saúde da população sugerem estar entre os principais rebatimentos da urbanização dispersa observada mundialmente. Eles são processos de mesma medida e que ocorrem concomitantemente, pois todos estão estruturados e organizados sob a mesma lógica: a de apropriação do espaço urbano de diversas maneiras e em diferentes níveis hierárquicos e intensidades.

E se esse tipo de urbanização e a cidade pode ser caracterizado pela expansão territorial do tecido urbano, processo que já tem sido observado, por exemplo, a partir de mapeamentos históricos da transformação e aumento das malhas urbanas das cidades. Na escala global e regional, o mesmo exercício pode ser realizado articulando a intensidade e expansão das luzes noturnas à construção de infraestrutura e demanda de energia. Isso possibilita também a quantificação e o mapeamento por técnicas de sensoriamento remoto, conforme aplicações de Miranda, Gomes e Guimarães (2005), Schneider, Friedl e Potere (2009) e Zhou e outros (2015).

A estratégia de uso da técnica pode auxiliar inclusive determinados momentos da urbanização, tendo em vista as diferentes formações socioespaciais e contextos políticos das unidades espaciais admitidas.

\section{Cidade dispersa pelas luzes noturnas}

Neste trabalho, utilizou-se para mapeamento o domínio da escala global (mundo) e regional (recorte nacional dos países estudados - Brasil, Moçambique e Austrália) (Figura 1), nos anos de 1992, 2002 e 2012. 


\section{Figura 1 - Situação geográfica dos recortes nacionais de estudo}

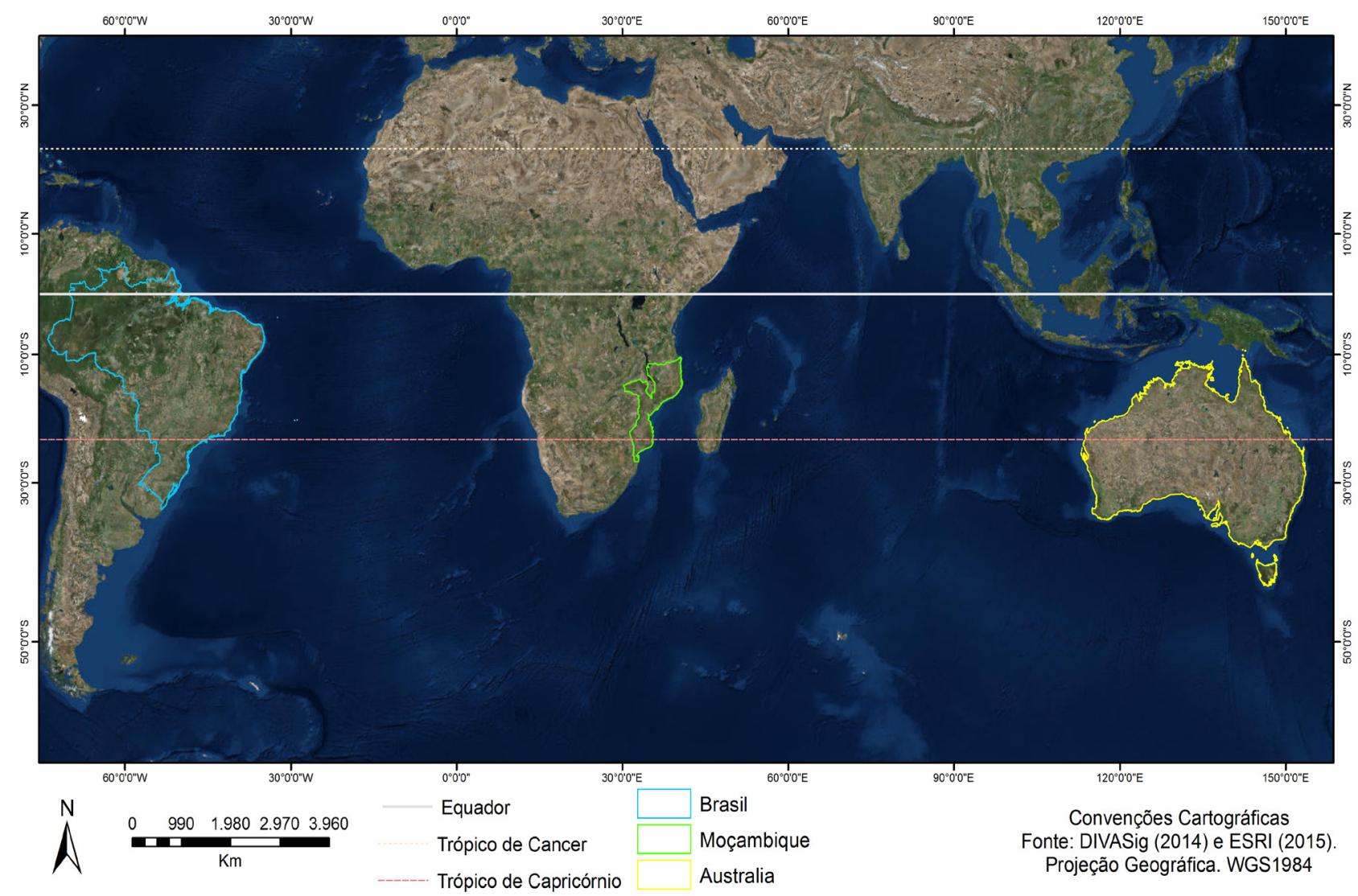

As imagens de luzes noturnas se referem aos produtos da série histórica da 4a versão de luzes noturnas da Defense Meteorological Satellite Program - Operational Linescan System (Version 4 DMSP-OLS Night time Lights Time Series), e coletadas pelo Department of Commerce da National Oceanic and Atmospheric Administration (NOAA, [s.d.]).

As imagens são produzidas no canal do visível e infravermelho, ambos são utilizados para monitorar a distribuição global de nuvens e temperatura do topo de nuvem duas vezes por dia, substituídos por valores Foto Multiplicador de Tubo (PMT) à noite. A resolução consiste em baixa resolução global e alta regional, com pixels de $3 \mathrm{~km}$.

A classificação foi desenvolvida de forma automática, utilizando como parâmetro de quantificação das áreas os pixels no histograma de cada imagem separadamente. O resultado é a separação de pixel com valor de 0 , denominadas Áreas não iluminadas; e os pixels com valores maiores que 1 (ou máximo de valores encontrado nas cenas), denominadas Áreas iluminadas.

O processamento foi realizado em ambiente de Sistemas de Informações Geográfica, utilizando para isso os softwares Idrisi ${ }^{\circledR}$ e ArcGis $10.1^{\circledR}$, e pode ser vista inicialmente na escala global na Figura 2.

As áreas dotadas de infraestrutura e indicadoras de construção de cidades são interpretadas, neste trabalho, em termos visuais, como a expansão das áreas iluminadas na escala mundial, nos anos de 1992, 2002 e 2012. Essas áreas iluminadas sugerem progressivo o aumento espaço temporal, não só em expansão horizontal, mas também de concentração e intensidade de determinadas áreas já consolidadas no primeiro ano da série. Tais resultados foram também verificados por Miranda, Gomes e Guimarães (2005), Schneider, Friedl e Potere (2009) e Zhou e outros (2015). 
Neste caso, os mapeamentos globais de áreas urbanas com base em luzes noturnas, sob a técnica de classificação de imagens noturnas entre áreas iluminadas e não iluminadas, indicam que as áreas iluminadas ocupam menos que 0,5\% de toda a superfície do planeta (Schneider; Friedl; Potere, 2009).

Essa particularidade é devido a uma característica metodológica no tratamento das imagens, que foi baseado na separação das áreas iluminadas e não iluminadas, relativas somente às áreas terrestres ou às ilhas urbanizadas, admitidas pelos recortes territoriais dos continentes. Trata-se de um critério deliberado que conduziu ao entendimento lógico que a urbanização dispersa não ocorre em toda a superfície do planeta. Ou seja, ele é exclusivo de áreas continentais ou de áreas que apresentam domínio de terra para expansão horizontal e intensificação local.

\section{Figura 2 - Crescimento de áreas iluminadas na escala mundial} 1992
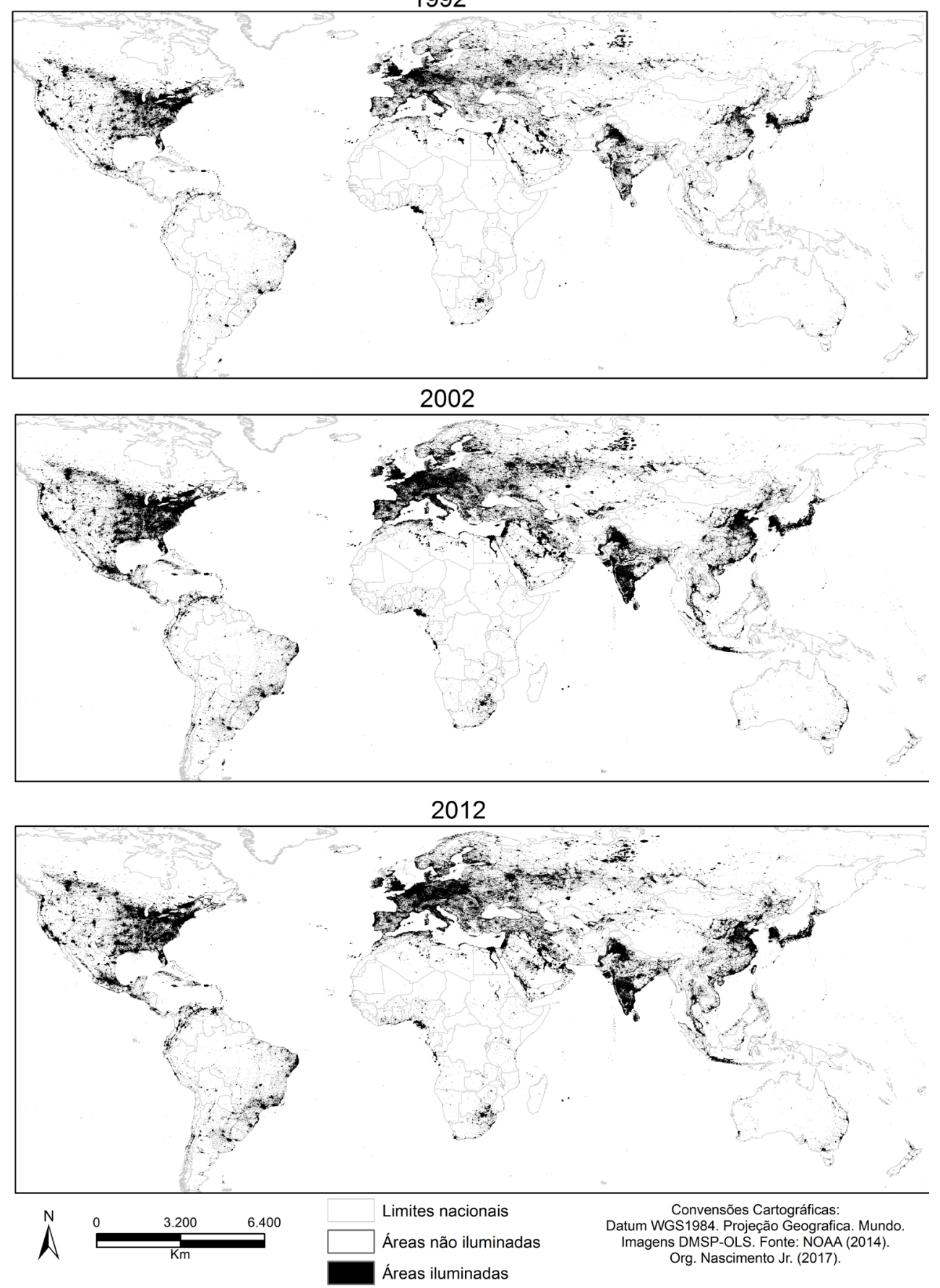
Contudo, em termos quantitativos os resultados aqui encontrados se diferiram de certa maneira de Schneider, Friedl e Potere (2009). Nesse caso, as áreas iluminadas ocorrem em cerca de 2,5\% em 1992, e entre 3,9\% em 2002 e 2012 (Tabela 1). Deste ponto de vista, na escala mundial (Figura 2), a urbanização é também concentração, uma vez que América do Norte, Europa, leste e sul asiático são majoritariamente as áreas que mais apresentam ganho no tempo, mesmo que apresenta estagnação a nível global, em termos quantitativos.

Tabela 1-Razão entre áreas iluminadas nos recortes territoriais admitid
\begin{tabular}{lccc}
\hline área iluminada & 1992 & 2002 & 2012 \\
\hline global & 2,5 & 3,9 & 3,9 \\
Brasil & 3,6 & 6,6 & 8,5 \\
Moçambique & 0,2 & 0,6 & 1,3 \\
Austrália & 1,0 & 2,0 & 1,9 \\
\hline
\end{tabular}

organização: $\bigcirc$ autor.

De outro modo, na escala nacional (Figuras 3, 4 e 5), a expansão de áreas iluminadas pode ser mapeada com maior destaque e precisão. Nessa escala, a resolução das imagens (3 $\mathrm{km}$ ) é suficiente para contemplar, principalmente no Brasil, uma ruptura forte mais visível entre a década de 1990 e 2000. Em Moçambique, esse momento é observado somente na década seguinte - 2000 para 2010. Na Austrália, não pode ser observado, em termos visuais, aumento expressivo de luzes noturnas.

\section{Figura 3 - Crescimento de áreas iluminadas no Brasil de 1992 a 2012}
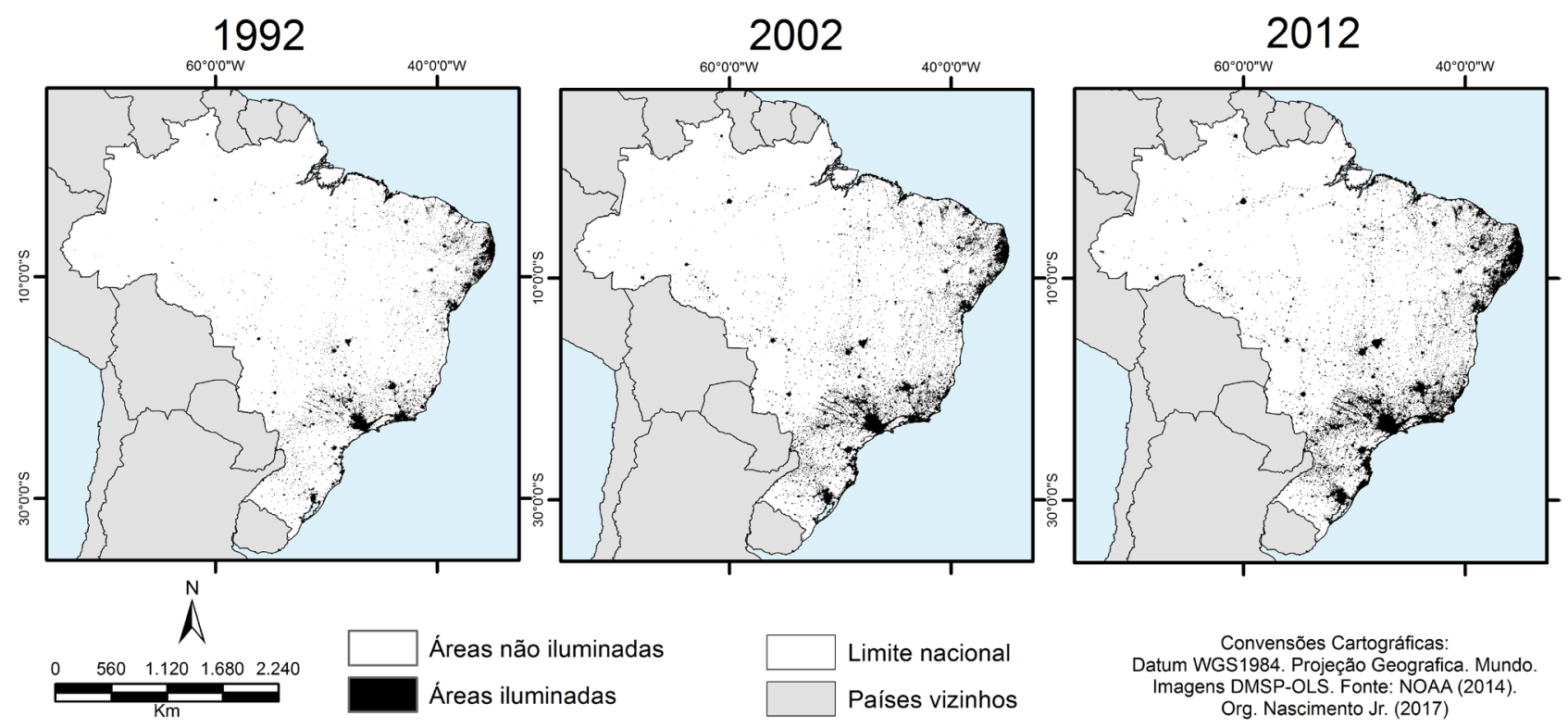

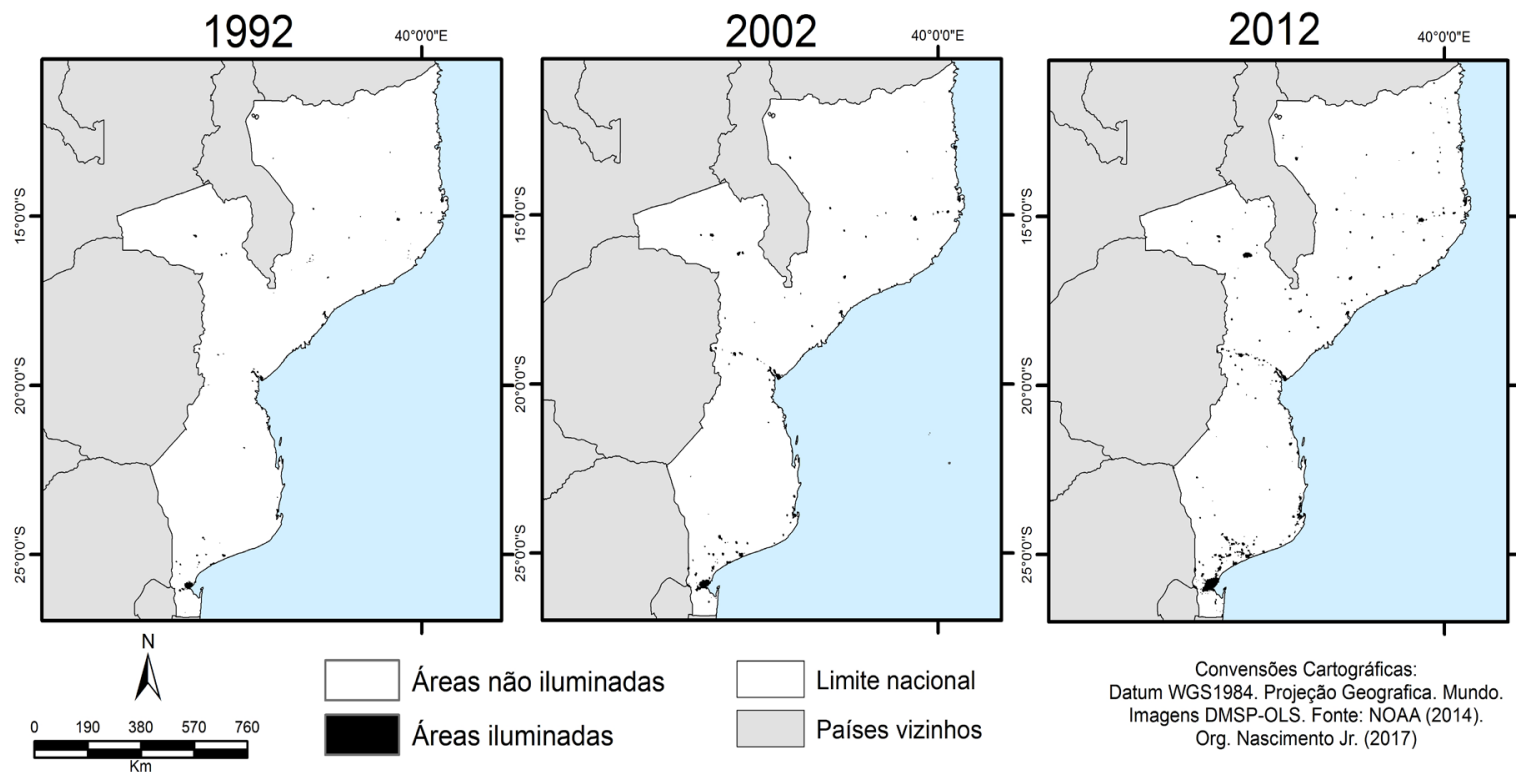

Figura 5 - Crescimento de áreas iluminadas na Austrália de 1992 a 2012

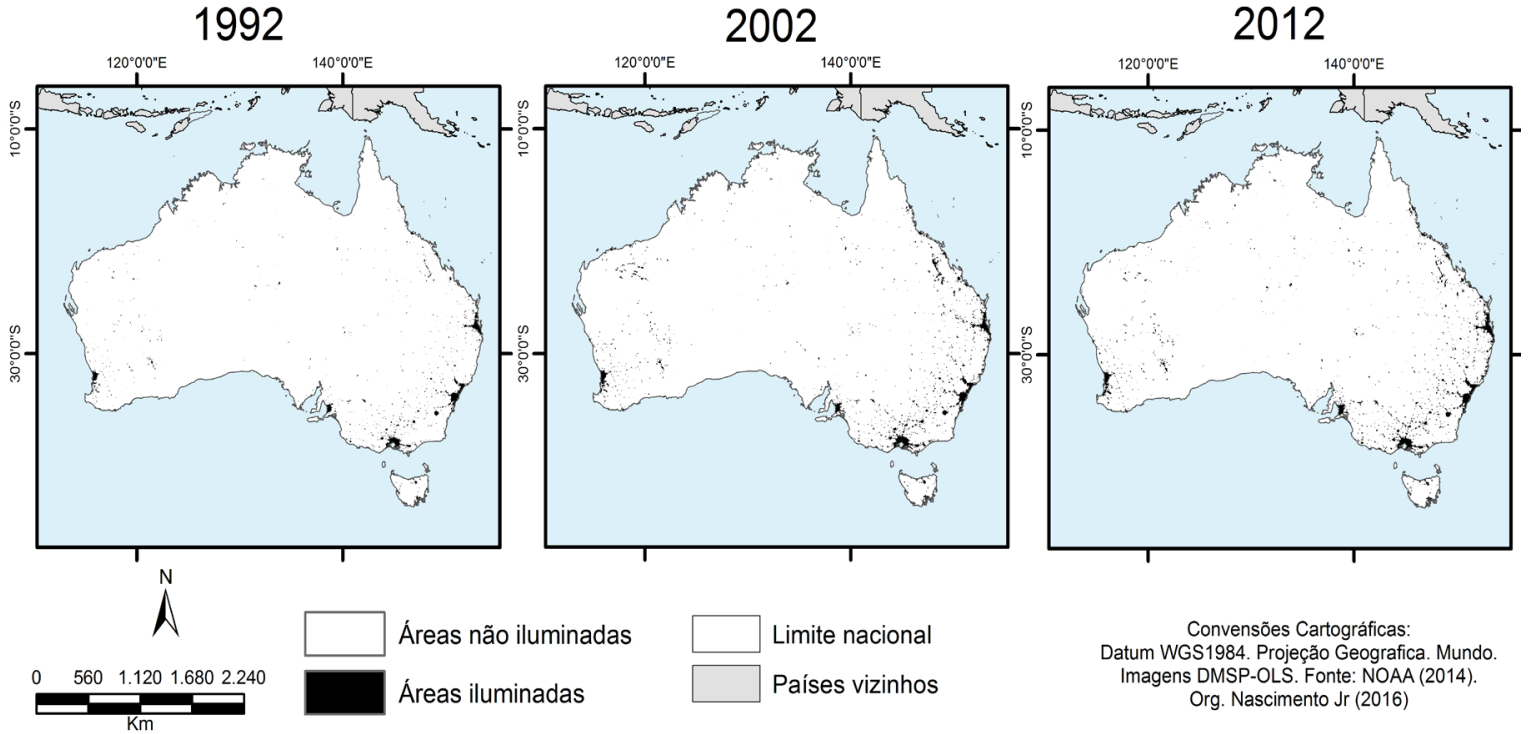

Entre os três países, o Brasil também é o que apresenta o maior índice de área iluminada (8,5\% da área do país em 2012), seguido em termos visuais e relativos pela Austrália (1,9) e Moçambique (1,3\%) (Tabela 1).

Um aspecto interessante de se destacar é a relação entre dispersão-intensidade-concentração em todas as escalas observadas. Nesse caso, são as áreas iluminadas equivalentes às maiores cidades que apresentam a configuração mais importante de aumento, concentração e intensidade de áreas iluminadas em direção a espaços e a áreas vizinhas.

Tal elemento assegura a urbanização dispersa não só como uma característica de expansão horizontal da área urbana construída, conforme inicialmente discutido e proposto por Bruegmann (2005), Botelho (2012), Sposito (2007) e Newman e Kenworthy (1999), mas também garante a importância e consolidação de determinadas configurações de rede urbana e da implementação de infraestruturas urbanas. 
Por outro lado, as áreas iluminadas equivalentes às maiores cidades apresentam de forma importante o aumento da intensidade de luzes. Trata-se de uma tendência interessante de se destacar, uma vez que a relação entre dispersão-intensidade-concentração não se configura só em termos de expansão horizontal da área urbana construída em áreas iluminadas, mas também de áreas consolidadas como, por exemplo, das principais cidades.

Esse aspecto pode ser observado no Brasil pela ocorrência de áreas iluminadas na região Sudeste, Sul, leste do Nordeste e nas áreas relativas às cidades de Brasília, Goiânia e Manaus. Em Moçambique, as áreas iluminadas são mais destacadas no setor relativo à região metropolitana da Cidade de Maputo e das cidades que fazem parte do Corredor de Beira (região Centro) e Corredor de Nacala (Norte). Na Austrália, as áreas iluminadas são mais recorrentes no setor costeiro leste e sudeste, destacando as regiões metropolitanas de Sidney, Brisbane e Melbourne, principalmente.

As áreas iluminadas nos países estudados também evidenciam um processo clássico que indica tanto a concentração de luminosidade como urbanização dispersa em espaços e áreas vizinhas, quanto de consolidação desses espaços como centros urbanos mais antigos e importantes na rede.

Em termos temporais (com base no ano de 1992), quantitativos (razão entre áreas iluminadas e não iluminadas) e proporcionais (relação das áreas iluminadas em cada país separadamente), os índices de expansão se encontram entre 1,2\% em 2002 para 1,98 em 2012, no Brasil; e 0,74\% em 2002 e 1,9\% em 2012 para Moçambique (Figura 5).

\section{Figura 5 - Comparação das áreas iluminadas em 2002 e 2012 em relação a 1992}

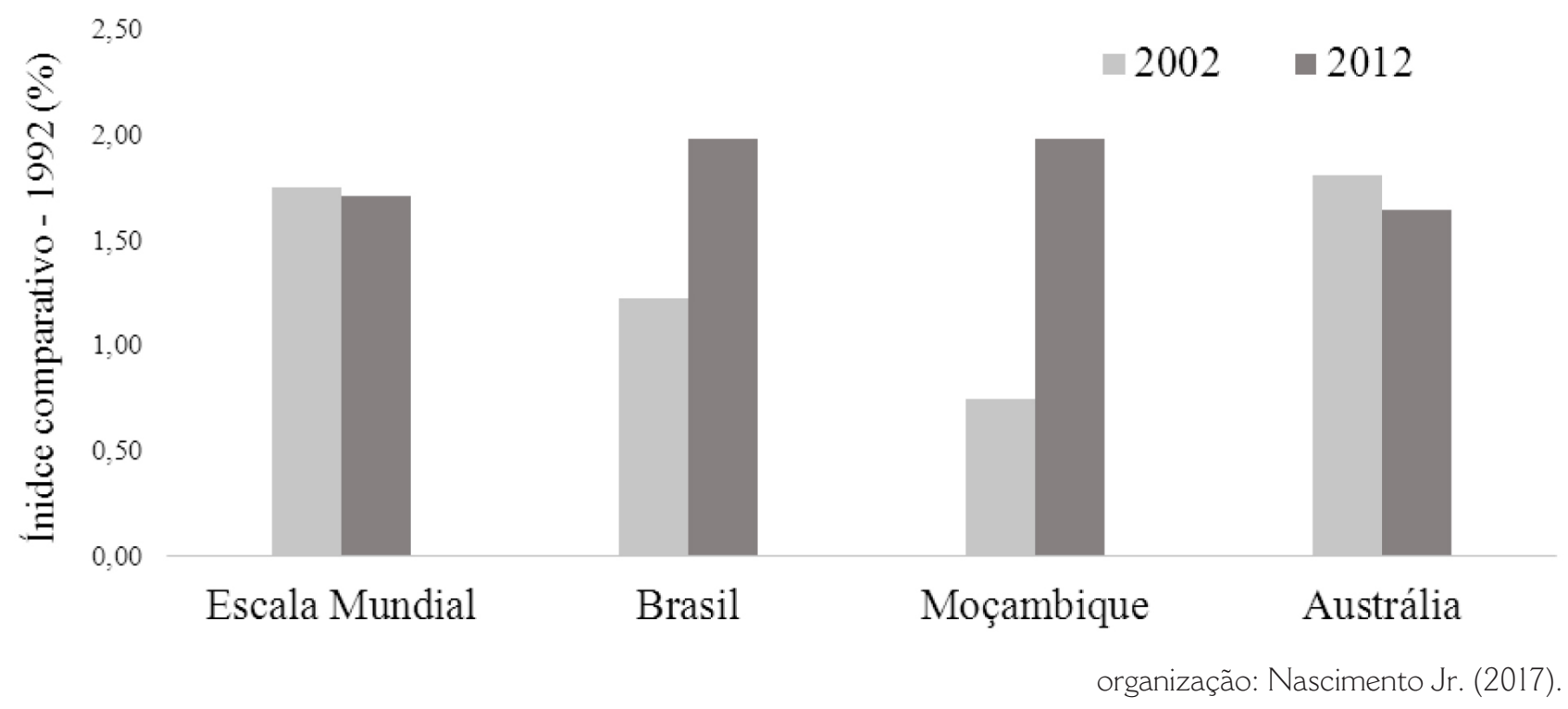

Sobre esse aspecto, algumas hipóteses explicativas podem ser associadas, e elas vão ao encontro principalmente da tendência de crescimento de áreas iluminadas e sua interiorização a partir de grandes investimentos advindos de políticas públicas de acesso à luz elétrica e à iluminação. 
Por exemplo, a experiência brasileira mostra que desde 2003 o Programa Luz para Todos tem beneficiado mais de 3 milhões de famílias e cerca de 15,9 milhões de moradores rurais de todo o país até outubro de 2016 (Luz para Todos, 2016). Em Moçambique, a instabilidade sociopolítica e econômica não permitiu a realização dos programas para expandir a rede elétrica nacional. Esses programas tornaram-se mais relevantes a partir de 1995 (EDM, [s.d.]), ainda que de forma mais lenta devido à dependência financeira, apresentaram impactos significativos entre os países estudados.

Mesmo que as luzes noturnas indiquem a presença da atividade humana, em locais onde não se pode inferir uma população residente, o acesso a luz elétrica e a iluminação se torna um indício de atividades que requerem infraestrutura e articulação entre cidades na rede urbana. Esse fato pode explicar a experiência brasileira e moçambicana nas últimas décadas.

Contraditoriamente, existe um efeito relativamente negativo associado à diminuição de áreas iluminadas. Esse crescimento negativo é observado na Austrália, cujo o valor comparativo em relação a 1992, sai de 1,80\%, em 2002, e vai para 1,64\%, em 2012, e é semelhante ao que ocorre em escala mundial, mas com outra medida quantitativa, entre 1,75\% em 2002 para 1,71\% em 2012. Esses números ainda carecem de mais estudos e observação em outros aspectos.

A proposta de relação entre áreas iluminadas parece ser funcional como um indicador de observação da cidade dispersa. Apesar do exercício quantitativo e cartográfico parecer interessante, mas na geografia é necessário ir além, isto é, colocando a conjugação da urbanização e da cidade, no entendimento e na determinação da urbanização dispersa como parâmetro de diferença e da comparação entre os mesmos.

\section{A urbanização dispersa no Brasil, em Moçambique e na Austrália}

De fato, a cidade é a protagonista e é a questão central do artigo. No entanto, entendê-la no processo de urbanização, é inseri-la dentro de um contexto mais amplo. Assim, a cidade é a materialização dos processos de produção, que além da descrição da distribuição espacial dos equipamentos, da identificação de padrões urbanos e da orientação da produção do espaço urbano, expressa também a situação e as lógicas contraditórias, desiguais e combinadas do desenvolvimento do capitalismo.

A relação da cidade a partir das imagens observadas remete à contextualização de processos explicativos da urbanização no interior de diferentes formações socioespaciais. Além desse aspecto, é possível considerar também os rebatimentos da urbanização dispersa por múltiplas dimensões, evidenciadas inicialmente pelos processos de autossegregação e periferização, degradação ambiental, encarecimento por distância e a qualidade na saúde da população.

Mas, as generalizações e particularidades de cada formação socioespacial no contexto da urbanização não eliminam o quadro de que em países socialmente desiguais o estudo da cidade dispersa oferece uma maior qualificação da urbanização.

Segundo a Organização das Nações Unidas (ONU, 2012), o Brasil se encontra entre os doze países mais socialmente desiguais do mundo, enquanto Moçambique ocupa a oitava posição entre os países mais pobres, por sua vez a Austrália é o segundo país com o maior Índice de Desenvolvimento Humano. 
Mesmo com essas disparidades, nos três casos, pode-se dizer que a urbanização de base colonial se consolidou a partir da ocupação costeira, e que sob a ampliação territorial das redes (não só a urbana), a urbanização constitui um ponto de intersecção entre as conexões externas (internacionais) e internas, de caráter local e orgânico (Santos, 2002).

Comparativamente, a estrutura e organização da formação socioespacial no Brasil e em Moçambique apresentam-se com características menos distintas do que em relação à Austrália. Entre os elementos possíveis que podem ser citados, destaca-se o caráter da propriedade privada que foi diferente nos três países devido ao tipo de colonização.

A diferença na Austrália é devido ao sistema penitenciário inglês, que oferecia a todos prisioneiros libertos ou que pagavam suas penas a garantia de um terreno. A lógica era de continuar a expansão do continente, reproduzindo-se por lá para não voltar à metrópole inglesa.

A experiência histórica australiana, associada ao conhecimento do território australiano e a capacidade organizacional de acesso à terra, favoreceu uma gestão urbana qualificada, com baixos níveis de segregação e aumento populacional, aceleração do processo de urbanização e industrialização.

Enquanto no Brasil e em Moçambique, a herança colonial não superada é até hoje marca principal das desigualdades socioespaciais, raciais e regionais do território, muito claramente observada não só nos conflitos pela terra e pelos recursos, como também no acesso e na qualidade da moradia, nos processos de discriminação e na pobreza social em dimensões materiais e raciais.

Essa particularidade da urbanização no Brasil e no Moçambique se efetiva, por exemplo, nas condições de moradia. Se por um lado, nesses países, a autossegregação é evidenciada na garantia pelo acesso à moradia em condomínio fechados (Sposito; Goes, 2013; Ojima; Marandola Jr., 2016; Maloa, 2016), do outro, ela é possível pela periferização por financiamento e construção de conjuntos habitacionais populares em áreas distantes da malha urbana consolidada (mas também no incremento de áreas urbanas sem a infraestrutura ideal (Ojima; Marandola Jr., 2016; Maloa, 2016).

A existência de aglomerados subnormais no Brasil" ${ }^{11}$ e dos assentamentos informais em Moçambique ${ }^{12}$ são exemplos empíricos desse modelo de urbanização.

Os aglomerados subnormais estão relacionados à forte especulação imobiliária e fundiária e ao decorrente espraiamento territorial do tecido urbano, à carência de infraestruturas das mais diversas, incluindo de transporte, e por fim, à periferização da população. Nesse contexto, os aglomerados são uma resposta de uma parcela da população à necessidade de moradia que habita em espaços pouco ou ainda não valorizados pelo setor imobiliário e fundiário dispersos pelo tecido urbano (IBGE, 2010).

11 Segundo o IBGE (2010), os aglomerados subnormais são um conjunto constituído por 51 ou mais unidades habitacionais, caracterizadas pela inexistência de título de propriedade, irregularidade nas vias de circulação, no tamanho e na forma dos lotes e/ou carência de serviços públicos essenciais (como coleta de lixo, rede de esgoto, rede de água, energia elétrica e iluminação pública).

12 Para a Direção Nacional de Planeamento e Ordenamento Territorial (Dinapot, 2006), trata-se de aglomerados humanos que se caracterizam pela falta de acesso a serviços de saneamento e água potável, espaço suficiente interior/exterior, vias de acesso e habitação segura e durável. São áreas cuja densidade habitacional é cerca de 67 habitações/ha, onde os terrenos não estão ordenados ou definidos, não há definição de arruamento e apresentam infraestrutura urbana básica ineficiente. 
Em Moçambique, o Programa das Nações Unidas para os Assentamentos Humanos (UN-Habitat, 2005) estima que $80 \%$ das populações nas cidades moçambicanas vivem em assentamentos informais. Para Raposo e Salvador (2007), os assentamentos informais são áreas de materialização do sincretismo e interação entre o mundo urbano de origem colonial e ocidental e o mundo rural moçambicano, onde os padrões de vida se afastam das referências rurais, mas também não seguem as citadinas do centro.

Nessa lógica, as áreas de assentamentos informais expandem-se, consolidam-se e densificam-se, repercutindo na saturação dos equipamentos e infraestruturas e na sua insuficiência, na dificuldade de acesso à educação e à saúde, no desemprego e na economia informal, na pobreza urbana, na emergência de problemas ambientais e sociais, entre outros problemas (Mello, 2007).

Se no Brasil e em Moçambique a característica principal da cidade dispersa é a segregação socioespacial, e junto com ela a autossegregação, a periferização e degradação ambiental (qualidade de infraestruturas, condições de moradia e funções ecológicas da cidade). Na Austrália também é, mas ela é admitida como suburbanização (distância do centro consolidado), que não escapa à segregação socioespacial, mas absorve outro grau de intensidade e efeitos, sendo mais relativa à oferta de emprego, qualidade de vida e fatores migratórios.

Conforme Rowland (1977), o subproduto da urbanização dispersa na Austrália pode ser resumido na expressão "implosão populacional”, cunhada Philip Hauser. Este autor explica esse termo mediante o crescimento concentrado de aglomerados urbanos metropolitanos em relação à dispersão da população, à complexidade das atividades econômicas, das unidades produtoras e consumidoras e à proximidade aos centros urbanos historicamente consolidados (Rowland, 1977).

O processo na Austrália é absorvido na tendência contínua de uma legislação de uso da terra em áreas consideradas agrícolas. Além disso, o automóvel, que também possibilitou a dispersão da população, tem promovido da mesma forma a escassez e o encarecimento dos custos de combustível. Desse modo, ele é um elemento que orienta a concentração da população nos centros metropolitanos e ao longo das rotas de transportes públicos.

Smith e Doherty (2006) explicam esse processo interpretando-o pelo conceito de suburbanização (bairros distantes do centro) e da noção sea change..$^{13}$ Nesse contexto, a urbanização também tem sido impulsionada pela migração de pessoas (entre capitais e entre centros regionais) que tem promovido pressões principalmente nas zonas costeiras (áreas mais densas de urbanização no país), e tem gerado significativas alterações nos padrões regionais do estilo de vida nas cidades costeiras.

As alterações são tanto de ordem socioeconômica (por meio do turismo) quanto socioambiental (pela degradação na forma de erosão e inundação). Essas mudanças colocam as cidades australianas em outro patamar de suporte de impactos da competição pelo emprego, e da fragilidade financeira e de segurança social (Smith; Doherty, 2006).

13 Segundo Smith e Doherty (2006), a noção sea change refere-se ao processo crescente de assentamento humano nas regiões costeiras da Austrália, particularmente em áreas fora dos espaços urbanos metropolitanos consolidados. 


\section{Considerações finais}

Apesar de ainda ser necessário aprofundar nos estudos para obter mais instrumentos tecnológicos e metodológicos que relacionem o conceito de cidade dispersa e sua gênese na urbanização dispersa, este artigo buscou aproximações a esse exercício a partir da conjugação de alguns atributos do processo de urbanização e da formação socioespacial dos países estudados.

A proposta de relacionar a urbanização e a cidade dispersa, a partir das imagens de luzes noturnas em duas escalas (mundial e nacional), nos períodos de 1992, 2002 e 2012, mostrou a funcionalidade de produtos de sensoriamento remoto como indicadores da expansão do tecido urbano em áreas dotadas de infraestrutura (iluminação, energia etc.).

Os resultados da classificação indicaram que as áreas iluminadas ocorrem entre até 3,9\% da superfície continental do planeta, sendo mais intensa na América do Norte, na Europa e no leste e sul asiático. No recorte nacional do Brasil, Moçambique e Austrália, as áreas iluminadas se referem a 8,5\%, 1,3\% e 1,9\% da área de cada país, respectivamente.

$\bigcirc$ aumento temporal de áreas iluminadas foi mais expressivo para Moçambique e Brasil, sendo esse resultado associado sobretudo a políticas públicas de iluminação, energia e infraestrutura. Contudo, na escala global e na Austrália, a tendência é de estagnação e diminuição.

No contexto global e regional, o mapeamento das áreas iluminadas oferece subsídios para evidenciar a continuidade de um processo clássico que se efetiva tanto na concentração de luminosidade em determinados espaços e em suas respectivas áreas vizinhas, quanto de sua consolidação histórica como centros mais importantes na rede urbana.

Neste estudo, mostrou-se que a urbanização e a cidade dispersa se dão pelo aumento da área ocupada, e se efetivam, nos casos brasileiro e moçambicano, pelo acesso à moradia, bem como nas condições de qualidade da residência e de seu entorno. Já na Austrália, concretizam-se como qualidade de vida da população, observada principalmente pela diminuição da eficiência e cumprimento da função social e ambiental nas cidades.

que se destaca é que esse modelo de urbanização se configura não só como um problema teórico-metodológico, mas como uma questão de direito à cidade, pelo fato de se efetivar principalmente como segregação socioespacial. Uma vez legitimada, ela tende a ser o modelo viável, que ao mesmo tempo se mostra como uma face nociva das desigualdades na cidade.

Esse rebatimento é visível quando se avaliam os custos e a seletividade da implantação de sistemas técnicos de distribuição de serviços, infraestruturas e equipamentos, algo muito observado em cidades de países socialmente desiguais, como Brasil e Moçambique, porém não apenas nesses.

Ao longo do texto, discutiu-se o expressivo aumento de padrões contemporâneos da cidade (forma) e da urbanização (processo), associado aos modos de produção e ao fenômeno urbano (conteúdo). No que se refere às recentes constituições da expansão do tecido urbano e suas contradições, constatou-se que elas não são uma tendência natural e espontânea, ao contrário, são modelos obedientes à lógica de reprodução das relações sociais de produção. 


\section{Referências}

AMARO, A. B. O processo de dispersão urbana e a questão ambiental: uma comparação da literatura estrangeira com o fenômeno no Brasil. Revista Formação (Online), 2016. No prelo.

BOTELHO, A. Capital volátil, cidade dispersa, espaço segregado: algumas notas sobre a dinâmica do urbano contemporâneo. Cadernos Metrópole, São Paulo, v. 14, n. 28, p. 297-315, jul./dez. 2012.

BRUEGMANN, R. La dispersión urbana: una historia condensada. Barcelona: Doce Calle, 2005.

CATALÃO, I. F. Diferença, dispersão e fragmentação socioespacial: explorações metropolitanas em Brasilia e Curitiba. Tese (Doutorado em Geografia) - Faculdade de Ciências e Tecnologia, Universidade Estadual Paulista, Presidente Prudente, 2013.

DINAPOT. DIREÇÃO NACIONAL DE PLANEJAMENTO E ORDENAMENTOTERRITORIAL. Moçambique, melhoramento dos assentamentos informais, análise da situação e proposta de estratégias de intervenção: relatório. Maputo: CEDH, 2006.

EDM. ELECTRICIDADE DE MOÇAMBIQUE, E. P. Governo de Moçambique. Disponível em: http://www.edm.co.mz/index.php. Acesso: 20 nov. 2016.

EEA. EUROPEAN ENVIRONMENT AGENCY. Urban sprawl in Europe: The ignored challenge. Office for Official Publications of the European Communities, 2006. Disponível em: http://www.eea.europa.eu/publications/eea_report_2006_10. Acesso em: 30 abr. 2015.

EID, J. et al. Fat city: Questioning the relationship between urban sprawl and obesity. Journal of Urban Economics, v. 63, p. 385-404, 2008.

GARDEN, F. L.; JALALUDIN, B. B. Impact of urban sprawl on overweight, obesity, and physical activity in Sydney, Australia. Journal of Urban Health, v. 86, n. 1, p. 19-30, 2009.

GONÇALVES, A. R. Indicadores da dispersão urbana. Dissertação (Mestrado em Planejamento Urbano e Regional) - Faculdade de Arquitetura, Universidade Federal do Rio Grande do Sul, Porto Alegre, 2011.

IBGE. INSTITUTO BRASILEIRO DE GEOGRAFIA E ESTATÍSTICA. Censo demográfico: resultado do universo. Rio de Janeiro: IBGE, 2010.

LEFEBVRE, H. Lógica formal/lógica dialética. Rio de Janeiro: Civilização Brasileira, 1975.

LUZ PARA TODOS. Ministério de Minas e Energia. Programa Luz para Todos. Disponível em: https://www.mme.gov.br/luzparatodos/asp/. Acesso: 20 nov. 2016.

MALOA, J. Urbanização moçambicana: uma proposta de interpretação. Tese (Doutorado em Geografia Humana) - Faculdade de Filosofia, Letras e Ciências Humanas, Universidade de São Paulo, São Paulo, 2016. 
MELLO, G. H. Expansão e estrutura urbana de Santos-SP: aspectos da periferização, da deterioração, da intervenção urbana, da verticalização e da sociabilidade. Tese (Doutorado em Sociologia) - Faculdade de Filosofia, Letras e Ciências Humanas, Universidade de São Paulo, São Paulo, 2007.

MIRANDA, E. E.; GOMES, E. G.; GUIMARÃES, M. Mapeamento e estimativa da área urbanizada do Brasil com base em imagens orbitais e modelos estatísticos. In: SIMPÓSIO BRASILEIRO DE SENSORIAMENTO REMOTO (SBSR), 2005, Goiânia. Anais... São José dos Campos, 2005. p. 3813-3820.

NEWMAN, P.W. G.; KENWORTHY, J. R. Sustainability and Cities: Overcoming Automobile Dependence. Washington, DC: Island Press, 1999.

NOAA. NATIONAL OCEANIC AND ATMOSPHERIC ADMINISTRATION. Defense Meteorological Satellite Program: Operational Linescan System. Version 4 DMSPOLS Nighttime Lights Time Series. Department of Commerce. Disponível em: http://ngdc.noaa.gov/eog/dmsp/downloadV4composites.html. Acesso: 3 ago. 2014.

NUNES, L. H. Urbanização e desastres naturais. São Paulo: Oficina de Textos, 2015.

OJIMA, R.; MARANDOLA JR., E. (Org.). Dispersão urbana e mobilidade populacional: implicações para o planejamento urbano e regional. São Paulo: Blucher, 2016.

OJIMA, R.; MONTEIRO, F. F; NASCIMENTO, T. C. L. Urbanização dispersa e mobilidade no contexto metropolitano de Natal: a dinâmica da população e a ampliação do espaço de vida. Urbe - Revista Brasileira de Gestão Urbana, Paraná, v. 7, n. 1, p. 9-20, 2015.

ONU. ORGANIZAÇÃO DAS NAÇÕES UNIDAS. World urbanization prospects: the 2011 revision. New York: United Nations, 2012. Disponível em: http://esa.un.org/ unup/pdf/FINAL_REPORT\%20WUP2011_Annextables_01Aug2012_Final.pdf. Acesso em: 17 set. 2014.

RAPOSO, I.; SALVADOR, C. Há diferença: ali é cidade, aqui é subúrbio: urbanidade dos bairros, tipos e estratégias de habitação em Luanda e Maputo. In: OPPENHEIMER, J.; RAPOSO, I. (Coord.). Subúrbios Luanda e Maputo. Lisboa: Colibri, 2007. p. $105-138$.

ROWLAND, D. T. Theories of urbanization in Australia. Geographical Review, v. 67, n. 2, p. 167-176, 1977.

SANTOS, M. A natureza do espaço: técnica e tempo, razão e emoção. 3. ed. São Paulo: Edusp, 2002.

A urbanização brasileira. 2. ed. São Paulo: Hucitec, 1993.

SCHNEIDER, A.; FRIEDL, M. A.; POTERE, D. A new map of global urban extent from MODIS satellite data. Environmental Research Letters, v. 4, n. 4, p. 1-11, 2009.

SILVA, E. T. Estrutura urbana e mobilidade espacial nas metrópoles. Rio de Janeiro: Letra Capital, 2013. 
SMITH, T.; DOHERTY, M. The suburbanisation of coastal Australia. Canberra: Australia State of the Environment Committee/Department of Environment and Heritage, 2006.

SPOSITO, M. E. B. Segregação socioespacial e centralidade urbana. In: VASCONCELOS, P. A.; CORREAA, R. L.; PINTAUDI, S. M. (Org.). A cidade contemporânea: segregação espacial. São Paulo: Contexto, 2010. p. 61-93.

. Novas formas de produção do espaço urbano no estado de São Paulo. In: REIS, N. G.; TANAKA, M. S. (Org.). Brasil, estudos sobre a dispersão urbana. São Paulo: Fauusp/Fapesp, 2007. p. 7-28

Capitalismo e urbanização. 15. ed. São Paulo: Contexto, 2005.

; GÓES, E. M. Espaços fechados e cidades: insegurança urbana e fragmentação socioespacial. São Paulo: Ed. Unesp, 2013.

SQUIRES, G. D. Urban Sprawl: Causes, Consequences \& Policy Responses. Washington: Urban Institute Press, 2002.

UN-HABITAT. Programa das Nações Unidas para assentamentos humanos. Escritório Regional para África e Estados Árabes. Estudo do Perfil Regional do Sector Urbano em Moçambique, 2005.

WHO. WORLD HEALTH ORGANIZATION. Obesity and overweight. Fact sheet, 2003. Disponível em: http://www.who.int/dietphysicalactivity/media/en/gsfs_obesity.pdf.>. Acesso em: 21 out. 2014.

ZHAO, Z.; KAESTNER, R. Effects of urban sprawl on obesity. Journal of Health Economics, n. 29, p. 779-787, 2010.

ZHOU, Y. et al. A global map of urban extent from nightlights. Environmental Research Letters, v. 10, n. 5, p. 1-11, 2015. 